\title{
Transcatheter valve implantation for patients with aortic stenosis: a position statement from the European Association of Cardio-Thoracic Surgery (EACTS) and the European Society of Cardiology (ESC), in collaboration with the European Association of Percutaneous Cardiovascular Interventions (EAPCI) ${ }^{\text {in }}$
}

\author{
Alec Vahanian ${ }^{\mathrm{a}, *}$, Ottavio R. Alfieri ${ }^{\mathrm{b}, * *}$, Nawwar Al-Attar ${ }^{\mathrm{a}}$, Manuel J. Antunes ${ }^{\mathrm{c}}$, \\ Jeroen Bax ${ }^{d}$, Bertrand Cormier ${ }^{\mathrm{e}}$, Alain Cribier $^{\mathrm{f}}$, Peter De Jaegere ${ }^{\mathrm{g}}$, Gerard Fournial ${ }^{\mathrm{h}}$, \\ Arie Pieter Kappetein ${ }^{\mathrm{g}}$, Jan Kovac ${ }^{i}$, Susanne Ludgate $^{j}$, Francesco Maisano $^{\mathrm{b}}$, Neil Moat ${ }^{k}$, \\ Friedrich-Wilhelm Mohr ${ }^{l}$, Patrick Nataf ${ }^{a}$, Luc Pierard ${ }^{m}$, José Luis Pomar ${ }^{n}$, \\ Joachim Schofer ${ }^{\circ}$, Pilar Tornos ${ }^{\mathrm{p}}$, Murat Tuzcu ${ }^{\mathrm{q}}$, Ben van Hout ${ }^{\mathrm{r}}$, \\ Ludwig K. von Segesser ${ }^{\mathrm{s}}$, Thomas Walther ${ }^{\prime}$

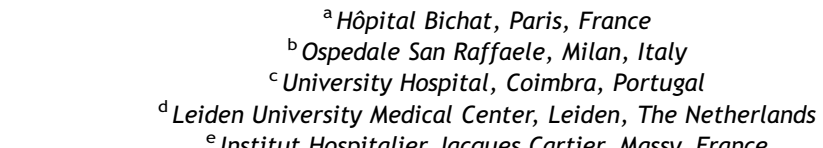 \\ e Institut Hospitalier Jacques Cartier, Massy, France \\ ${ }^{\mathrm{f}} \mathrm{CHU}$ de Rouen, Hôpitaux de Rouen, Hôpital Charles Nicolle, Rouen Cedex, France \\ ${ }^{\mathrm{g}}$ Thoraxcenter, Erasmus Medical Center, Rotterdam, The Netherlands \\ ${ }^{\mathrm{h}} \mathrm{CHU}$, Centre Hospitalier de Rangueil, Toulouse, France \\ i University Hospitals of Leicester, Leicester, UK \\ ${ }^{j}$ Department of Health, Medicines and Healthcare Products Regulatory Agency, London, UK \\ ${ }^{\mathrm{k}}$ Royal Brompton Hospital, London, UK \\ 'Heart Center Leipzig, University of Leipzig, Leipzig, Germany \\ m University Hospital Sart Tilman, Liege, Belgium \\ ${ }^{\mathrm{n}}$ Hospital Clinico de Barcelona, University of Barcelona, Barcelona, Spain \\ ${ }^{\circ}$ Hamburg University Cardiovascular Center, Hamburg, Germany \\ P Hospital Universitari Vall d'Hebron, Barcelona, Spain \\ ${ }^{\mathrm{q}}$ Cleveland Clinic, Cleveland, $\mathrm{OH}$, USA \\ r Julius Center for Health Sciences and Primary Care, University Medical Center Utrecht, Utrecht, The Netherlands \\ ${ }^{\mathrm{s}}$ CHUV, Lausanne, Switzerland
}

Received 3 April 2008; received in revised form 3 April 2008; accepted 15 April 2008; Available online 27 May 2008

\begin{abstract}
Aims: To critically review the available transcatheter aortic valve implantation techniques and their results, as well as propose recommendations for their use and development. Methods and results: A committee of experts including European Association of Cardio-Thoracic Surgery and European Society of Cardiology representatives met to reach a consensus based on the analysis of the available data obtained with transcatheter aortic valve implantation and their own experience. The evidence suggests that this technique is feasible and provides haemodynamic and clinical improvement for up to 2 years in patients with severe symptomatic aortic stenosis at high risk or with contraindications for surgery. Questions remain mainly concerning safety and long-term durability, which have to be assessed. Surgeons and cardiologists working as a team should select
\end{abstract}

\footnotetext{
The following authors declared the following conflicts of interest: J.B., research grants from GE Healthcare, BMS Medical Imaging, St Jude, Medtronic, Boston Scientific; A.C., consultant for Edwards Lifesciences; J.K., consultant for Medtronic; F.M., consultant for Edwards Lifesciences and Medtronic, consultant and stockholder for Micardia; P.N., consultant for Sorin; J.L.P., consultant for Edwards Lifesciences and Boston Scientific; A.V., consultant for Edwards Lifesciences; B.v.H., scientific director on a cost effectiveness study concerning PVR sponsored by Edwards Lifesciences; L.K.v.S., founder and shareholder of Smartcanula LLC, Lausanne, Switzerland. All other authors have no conflicts of interest to declare. Funding: Edwards Lifesciences provided an unrestricted grant for the practical organization of the meeting. No representatives of Edwards Lifesciences attended the meeting or were involved in the elaboration of the document.
} 
candidates, perform the procedure, and assess the results. Today, the use of this technique should be restricted to high-risk patients or those with contraindications for surgery. However, this may be extended to lower risk patients if the initial promise holds to be true after careful evaluation. Conclusion: Transcatheter aortic valve implantation is a promising technique, which may offer an alternative to conventional surgery for highrisk patients with aortic stenosis. Today, careful evaluation is needed to avoid the risk of uncontrolled diffusion.

(C) 2008 The European Society of Cardiology, European Association for Cardio-Thoracic Surgery, and Europa Edition. All rights reserved.

Keywords: Aortic stenosis; Valve disease; Percutaneous valve interventions

\section{Preamble}

Valve disease is an important public health problem, as it carries a poor prognosis and its prevalence is strongly linked to the phenomenon of population ageing [1]. The most frequent native valve disease in Europe is currently aortic stenosis (AS), which is most often seen in elderly patients with comorbidities [2]. Valve replacement is the definitive therapy for patients with severe AS who have symptoms or objective consequences such as left ventricular (LV) dysfunction $[3,4]$. Operative mortality is quite low, even in elderly patients when properly selected, and long-term results have been shown to be satisfactory $[5,6]$. However, the risk of surgery may be higher in elderly patients with significant comorbidities. In addition, several registries show that referring physicians often do not propose surgery, as was the case in the Euro Heart Survey with 33\% of patients with severe valve disease and severe symptoms not being considered for surgery [7]. Thus, despite the good results of valve surgery, there may well be a role for less invasive alternatives.

Balloon aortic valvuloplasty (BAV) is now rarely used, mainly due to its limited long-term efficacy [2].

Six years after the first-in-man [8], transcatheter aortic valve implantation (TAVI) for the treatment of AS currently represents a dynamic field of research and development: two devices have been CE-marked and are being commercialized.

At this point in time, it is important for professional societies to critically review the available TAVI techniques and their results, as well as propose recommendations for their use, development in clinical practice, and further research $[9,10]$. On the 18-19th of November 2007, a committee of experts, including EACTS and ESC representatives, met. The consensus reached is summarized in the current document, which was approved first by the committee members and subsequently by the board of both professional societies involved.

The Committee acknowledges that the conclusions in this document rely on limited data reported mostly in oral communications and few in peer-reviewed journals and are temporally limited by the very nature of the document.

\section{Current techniques and results}

Two devices are under clinical investigation for TAVI. One device is the Edwards-Sapien valve (Edwards Lifesciences Inc., CA, USA), which consists of three pericardial leaflets, initially equine and currently bovine, mounted within a tubular, slotted, stainless steel, balloon-expandable stent. It is currently available in 23 and $26 \mathrm{~mm}$ sizes, necessitating, for the transfemoral approach, respectively, 22 and $24 \mathrm{~F}$ introducer sheaths, and for the transapical approach, this measurement was $33 \mathrm{~F}$ and is now $26 \mathrm{~F}$. The other device is the CoreValve Revalving System (CRS TM, CoreValve Inc., Irvine, CA, USA), which has three pericardial leaflets, initially bovine and currently porcine, mounted in a self-expanding, nitinol frame. It is available in 26 and $29 \mathrm{~mm}$ sizes, which go through an $18 \mathrm{~F}$ introducer for transfemoral use, or very recently $21 \mathrm{~F}$ for the transapical route. (NB: the measurements of prosthesis size quoted by the manufacturers do not correspond exactly to those of surgically implanted prostheses.)

\subsection{Techniques of implantation}

TAVI is currently carried out using two different approaches (retrograde transfemoral and anterograde transapical), which share the same main principles.

- Most teams perform the procedure under general anaesthesia, although sedation and analgesia may suffice for the transfemoral approach.

- Peri-procedural transoesophageal echocardiography (TEE) monitoring is desirable to correctly position the valve as well as to detect complications.

- After crossing the aortic valve, BAV is performed to predilate the native valve and serve as a rehearsal for TAVI. Simultaneous rapid pacing decreases cardiac output, stabilizing the balloon during inflation. Normal blood pressure must be completely recovered between sequences of rapid pacing.

- The following imaging methods can be used to position the prosthesis at the aortic valve:

- Fluoroscopy to assess the level of valve calcification.

- Aortography, using different views, performed at the beginning of the procedure and eventually repeated with the undeployed prosthesis in place, to determine the position of the valve and the plane of alignment of the aortic cusps.

- Echocardiography: TEE is helpful, in particular, in cases with moderate calcification. The additional value of three-dimensional real-time TEE is currently being evaluated. According to the limited current experience with intracardiac echography, it does not seem to add to TEE in this setting.

- When positioning is considered correct, the prosthesis is released. Rapid pacing is used at this stage in balloon expandable but not in self-expanding devices.

- Immediately after TAVI, aortography and, whenever available, TEE or, in the absence of TEE, eventually Transthoracic echo-cardiogram (TTE) are performed to assess the location and degree of aortic regurgitation and the patency of the coronary arteries and to rule out 
complications such as haemopericardium, and aortic dissection. The haemodynamic results are assessed using pressure recordings and/or echocardiography.

- After the procedure, the patients should stay in intensive care for at least $24 \mathrm{~h}$ and be closely monitored for several days especially as regards haemodynamics, vascular access, rhythm disturbances (especially late atrioventricular block), and renal function.

The following are the specific issues related to the different approaches.

In the transfemoral approach, close attention should be paid to the vascular access.

The common femoral artery can be either prepared surgically or approached percutaneously. Echo-guided femoral access could be useful. Manipulation of the introductory sheaths should be careful and fluoroscopically guided. Depending on the size of the device, closure of the vascular access can be effected surgically or using a percutaneous closure device [11].

For the transapical approach, femoral access and cardiopulmonary bypass should be on standby in patients in whom surgical conversion is an option in case of complications. The technique requires an antero-lateral mini-thoracotomy, pericardiotomy, identification of the apex, and then puncture of the left ventricle using a needle through purse-string sutures. Subsequently, an introductory sheath is positioned in the LV, and the prosthesis is implanted using the anterograde route.

\subsection{Results}

Since the first-in-man TAVI by Alain Cribier in 2002, well over 1000 high-risk patients with severe symptomatic AS have been treated using TAVI (as of January 2008).

\subsubsection{Transfemoral approach}

Over 400 cases have been performed using the balloonexpandable and another 500 using the self-expandable prosthesis (Company sources January 2008). Reports originate from a limited number of centres worldwide [12-17]. The patients treated were mostly $>80$ years old, at high risk (e.g. Logistic EuroScore $>20 \%$ in most cases), or with contraindications for surgery.

The overall results can be summarized as follows:

Procedural success is closely linked to experience and is $\sim 90 \%$ in experienced centres. A learning curve can also be observed resulting in better patient selection and outcomes. Valve function is good with a final valve area ranging from 1.5 to $1.8 \mathrm{~cm}^{2}$.

Mortality at 30 days ranges from $5 \%$ to $18 \%$. Acute myocardial infarction occurs in $2-11 \%$. Coronary obstruction is rare $(<1 \%)$. Mild-to-moderate aortic regurgitation, mostly paravalvular, is observed in $\sim 50 \%$ of cases. However, the availability of larger prostheses and their more careful matching with the size of the aortic annulus led to the decrease in the incidence of severe aortic regurgitation to $\sim 5 \%$. Prosthesis embolisation is rare, $\sim 1 \%$.
Vascular complications, with an incidence ranging from $10 \%$ to $15 \%$, remain a significant cause of mortality and morbidity. Stroke ranges from 3\% to $9 \%$. Finally, atrioventricular block occurs in 4-8\%, necessitating pacemaker implantation in up to $24 \%$ with self-expandable devices.

Long-term results up to 2 years (though only 1 year in most studies) are reported in a limited number of patients. They show a survival rate of $70-80 \%$ with a significant improvement in clinical condition in most cases. The majority of late deaths are due to comorbidities.

Serial echocardiographic studies have consistently shown good prosthetic valve function with no structural deterioration of valve tissue.

\subsubsection{Transapical approach}

The total experience with transapical aortic valve implantation comprises over 300 patients, also at high risk for conventional surgery, even more so because of concomitant peripheral arterial disease in most cases. Experience currently reported only relates to the balloonexpandable prosthesis [18-21], although, the first-in-man has been recently performed with the self-expandable device.

The implantation success rate of the transapical procedure is $\sim 90 \%$. Over $70 \%$ of cases are done off pump, the figure being $90 \%$ in experienced centres, and the rate of perioperative conversion is $9-12 \%$. Mortality rates range from $9 \%$ to $18 \%$. The incidence-of stroke is $0-6 \%$. The quality of the results seems closely related to experience as well as the availability of high-quality imaging in the operating theatre [19].

There are currently no direct comparative studies available for the two approaches.

\subsection{Perspectives}

Progress in delivery systems and valve manufacturing could lead to lower profile, repositionable, retrievable, and more durable devices, as well as a wider range of prosthetic valve dimensions. Furthermore, improved imaging, such as online three-dimensional reconstruction and stereotaxis, could facilitate valve placement.

\subsection{Pending questions}

In the light of the current experience, bearing in mind the previously mentioned, inherent limitations of any conclusions, TAVI using both balloon- and self-expandable devices can be said to be feasible. Short- and mid-term haemodynamic results are good up to 2 years. However, the technique remains challenging, in particular, as regards vascular access, device sizing, and positioning. The major concerns as regards to safety are as follows:

- Vascular complications with the transfemoral approach, which should decrease with smaller devices.

- Stroke rate, in particular, when using the transfemoral approach.

- Long-term consequences of paravalvular leaks, even if mild-to-moderate regurgitation is considered not to have significant clinical consequences in the short-term. 
- Atrioventricular block, the incidence, timing, and predictors of which have to be identified more precisely.

Mid (short)-term clinical outcome is encouraging, however, long-term durability of these bioprostheses and the incidence of endocarditis or thrombo-embolic events remain key questions, especially if considering lowering the threshold for indication.

The feasibility of subsequent aortic valve intervention is not known.

\section{Recommendations for the development of transcatheter aortic valve implantation}

\subsection{Patient selection}

Selection of candidates for TAVI, especially risk assessment, should involve multi-disciplinary consultation between cardiologists, surgeons, imaging specialists, anaesthesiologists, and possibly other specialists if necessary.

TAVI is indicated in patients with calcified pure or predominant AS. It is unlikely that it will be used in patients with pure aortic regurgitation.

Degeneration of an implanted aortic bioprosthesis (valvein-valve implantation) is an attractive potential indication because of the high risk of re-operation in elderly patients. However, the current experience is too limited to make any recommendations.

The following are the four steps of patient selection:

- confirmation the severity of AS;

- evaluation of symptoms;

- analysis of the risk of surgery and evaluation of life expectancy and quality of life; and

- assessment of the feasibility and exclusion of contraindications for TAVI.

\subsubsection{Confirmation of the severity of aortic stenosis}

TAVI should be performed only in severe AS. Echocardiography is the preferred tool to assess the severity of AS according to a combination of measurements of valve area and flow-dependent indices. Low-dose dobutamine echocardiography is useful to differentiate between severe and the rare 'pseudo severe' AS in patients with low LV ejection fraction and low gradient $[3,4]$.

\subsubsection{Evaluation of symptoms}

At the present stage, TAVI should only be proposed in patients with severe symptoms that can definitely be attributed to valve disease because of pending questions on safety and valve durability.

\subsubsection{Analysis of the risks of surgery, and evaluation of life expectancy and quality of life}

Decision-making is particularly complex in these elderly patients who represent a heterogeneous population and require balanced and individualized analysis.

The evaluation of the risk of surgery is based on the assessment of cardiac and extra cardiac factors [22]. Risk scores, such as the EuroScore [23], the STS predicted risk of mortality score [24], or the Ambler score [25], are of interest. However, they all share similar limitations: predictive ability is reduced in these high-risk patients who represent only a small proportion of the population from which the scores were elaborated; and high-risk patients form a particularly heterogeneous group in which it is difficult to capture all the comorbidities. The value of individual scores in this high-risk population has yet to be specifically established [26]. The predictive value of these scores for morbidity and long-term results is also unknown.

TAVI should currently be restricted to patients at highrisk or with contraindications for surgery. It is premature to consider using it in patients who are good surgical candidates.

For the Committee, the key element to establish whether patients are at high risk for surgery is clinical judgement, which should be used in association with a more quantitative assessment, based on the combination of several scores (for example expected mortality $>20 \%$ with the Logistic EuroScore and $>10 \%$ with STS score). This approach allows the team to take into account risk factors that are not covered in scores but often seen in practice such as chest radiation, previous aorto-coronary bypass with patent grafts, porcelain aorta, liver cirrhosis, etc. Surgical risk estimation should also bear in mind results in the given institution [27].

At this stage, TAVI is not recommended for patients who simply refuse surgery on the basis of personal preference.

Life expectancy is most significantly influenced by comorbidities, which should be carefully looked for. In addition to clinical evaluation, semi-quantitative scoring systems, such as those used in geriatrics, may be helpful [28]. Today, TAVI is seldom considered in patients $<70$, however, age alone is not sufficient for its use instead of surgery. TAVI should not be performed in patients whose life expectancy is $<1$ year, who should be managed conservatively.

\subsubsection{Assessment of feasibility and exclusion of contraindications of transcatheter aortic valve implantation}

The following steps should be taken to assess the feasibility of TAVI.

3.1.4.1. Assessment of the coronary anatomy. Coronary angiography should be performed to this end. If associated coronary artery disease requires revascularization, whether to proceed surgically, percutaneously, or in a hybrid manner, as well as the chronology of interventions, should be the subject of individualized discussion based on the patient's clinical condition and anatomy. TAVI is probably not recommended in patients with severe proximal coronary stenoses not amenable to percutaneous coronary interventions.

The position of the coronary arteries relative to the aortic cusps can be assessed using aortography or multislice computed tomography [29].

3.1.4.2. Measurement of the aortic annulus. Correct sizing of the valve is critical to minimize the potential for paravalvular leakage and to avoid prosthesis migration 
after placement; however, a gold standard method of measurement has yet to be established. TEE has been found to show larger values than transthoracic echocardiography, thus, it should be performed if borderline values lead to doubt the feasibility of the procedure [30]. Multislice computed tomography [29] or magnetic resonance imaging could also be used for this purpose. Finally, aortography measurements performed during BAV are also useful.

Echocardiography is the preferred tool for the assessment of the morphology of the LV outflow tract and, before implanting self-expandable devices, the dimensions of the aortic root.

3.1.4.3. Evaluation of size, tortuosity, and calcification of peripheral arteries. Angiography is the reference; however, multislice computed tomography can also be used. Finally, magnetic resonance imaging is helpful in patients with renal insufficiency.

Some contraindications are general, whereas others are approach- or device-specific.

General contraindications for TAVI are as follows:

- Aortic annulus $<18$ or $>25$ mm for balloon-expandable and $<20$ or $>27$ for self-expandable devices.

- Bicuspid valves because of the risk of incomplete deployment of the prosthesis [31].

- Presence of asymmetric heavy valvular calcification, which may compress the coronary arteries during TAVI [15]. The bulk and distribution of calcification in the valve may be assessed by fluoroscopy and multislice computed tomography. Finally, the risk of coronary compression can be anticipated during BAV.

- Aortic root dimension $>45 \mathrm{~mm}$ at the aorto-tubular junction for self-expandable prostheses.

- Presence of apical LV thrombus.

The specific indications for transfemoral and transapical approaches are not fully established and should be discussed according to patient condition and local expertise.

Contraindications of the transfemoral approach are as follows:

- Iliac arteries: severe calcification, tortuosity, small diameter ( $<6-9 \mathrm{~mm}$ according to the device used), previous aorto-femoral bypass.

- Aorta: severe angulation, severe atheroma of the arch, coarctation, aneurysm of the abdominal aorta with protruding mural thrombus.

- Presence of bulky atherosclerosis of the ascending aorta and arch detected by TEE.

- Transverse ascending aorta (balloon-expandable device).

Contraindications for the transapical approach are as follows:

- previous surgery of the LV using a patch, such as the Dor procedure;

- calcified pericardium;

- severe respiratory insufficiency; and

- non-reachable LV apex.

\subsection{Performance of transcatheter aortic valve implantation}

The performance of TAVI, even more so ab initio, should be restricted to a limited number of high-volume centres, which have both cardiology and cardiac surgery departments, with expertise in structural heart disease intervention and high-risk valvular surgery.

The procedure requires the close cooperation of a team of specialists in valve disease, including clinical cardiologists, echocardiographists, interventional cardiologists, cardiac surgeons, and anaesthesiologists.

Interventional cardiologists should be experienced in catheter-based valvular interventions, and peripheral access using large devices.

Cardiac surgeons should be experienced in valve surgery and the management of complex cases.

The final organization may vary from centre to centre and according to the type of procedure.

A multidisciplinary team approach and cross-fertilization will be fundamental in the development of these procedures.

Because of the severe clinical condition of these patients, the presence of anaesthesiologists with specific expertise in cardiology is mandatory for peri- and post-operative care in collaboration with cardiologists and cardiovascular surgeons.

A close collaboration with surgeons skilled in vascular access repair and endo-vascular procedures is recommended for transfemoral aortic valve implantation.

The aim of TAVI training is to acquire basic, then advanced, and finally device-specific skills. It will concentrate on knowledge of valve disease (clinical assessment, catheterization techniques, imaging), working in a sterile environment, access management, understanding the equipment, and anticipation and treatment of complications. Training will be through didactic sessions, bench and/or computer simulators, animal laboratories, hands-on training, participation in established workshops, and proctoring during the first cases.

The field of teaching and certification needs to be significantly developed. A new subspecialization may be necessary with a common training pathway for cardiologists and surgeons wishing to practice TAVI.

At this early stage, data are insufficient to define a minimum number of procedures required for competency. Furthermore, individual experience must be continued in order to conserve skills.

As regards the logistics, it is agreed that the operating room and the catheterization laboratory should be as close as possible to guarantee optimum patient safety. The optimal environment for TAVI should be spacious and sterile, and feature high-quality imaging equipment, and haemodynamic monitoring and recording capabilities. However, where to find such an environment is still under debate, as both current surgical and interventional suites are suboptimal. Catheterization laboratories have good quality imaging but may not be sterile and may induce delay in rescue surgery. The opposite is often the case for operating rooms.

A hybrid suite is ideal as it fulfils the role of both an operating room and a catheterization laboratory. However, most institutions do not have a hybrid room available, thus, 
the organizational and financial implications of acquiring one, which is highly desirable, cannot be overlooked.

It is the role of professional organizations such as the EACTS and the ESC and their national equivalents to set the standards for performance of the procedure and training and accreditation on an individual and institutional level.

\subsection{Evaluation of the results}

Evaluation of the results of TAVI will present a significant challenge because of the unique characteristics of this patient population. Thus, comparison with current outcome standards may not be appropriate. Close collaboration between investigators, regulators, and the industry should be assured early on.

The evaluation of new devices or techniques should be performed in accordance with the stipulations of the regulating authorities [32,33]. In Europe, TAVI devices are classified in the highest risk group (class 3 ) as regards the requirements for the putting of new devices on the market [32]. Evaluation should adhere to the following pattern: bench testing, in vitro, and animal implantation studies (including bio-compatibility studies), then, only when sufficient data are available, clinical investigation.

Clinical investigation should begin with the proof of concept feasibility studies, followed by prospective clinical investigations to determine safety and performance [34].

Randomized trials are the most rigorous design to evaluate safety and efficacy in relation to other treatment modalities. However, this is difficult with TAVI in relation to the most high-risk patients, many of whom are currently not operated on mostly due to non-referral [7]. Furthermore, the contemporary natural history of unoperated patients is incompletely known.

The Committee believes that randomized trials are highly desirable once greater experience has been acquired, and only small modifications in the technology used are to be expected. The necessary clear definition of entry criteria for these trials may be hindered by the inadequacy of risk scores in these high-risk patients (see Section 3.1.3 for more details).

In high-risk operable patients, TAVI should be compared with valve replacement, in particular with the perspective of patients who are in better clinical condition in the future. In these patients, efficacy could be tested as non-inferiority vs surgery, avoiding a too large delta, whereas safety can be tested as superiority to surgery. In non-operable patients, TAVI can be compared with the best available medical treatment using the superiority design for efficacy; however, this is more debatable and probably more difficult to run. A randomized trial, PARTNER US, is currently ongoing where the primary endpoint is all-cause mortality at 1 year. In the future, the extension of TAVI to a lower risk patient population should occur only in the setting of a randomized trial.

As well as enrolment in randomized controlled trials, data should be accumulated in registries. Such registries, which may be regional, national, or international, are mandatory in the evaluation of TAVI before its release in the general medical community. Completeness of the data is essential here. The duration of follow-up to assess safety should be at least 1 year in the pre-market phase and ideally 5 years for post-marketing surveillance. Retrieval studies should also be carried out if appropriate.

Irrespective of the study design, safety and efficacy endpoints must be carefully defined.

Analysis will include the standard major adverse cardiac events: mortality (30 day, in hospital, 1 year), stroke, myocardial infarction, re-hospitalization, reoperation, arrhythmias, and conduction disturbances. All adverse events, anticipated and non-anticipated, should also be reported to the health authority. Quality of life is paramount, in particular, in these populations; thus, improvement should be recorded using quality of life metrics, which should be combined with cost effectiveness parameters. Endpoints assessing valve function should follow the guidelines developed for valve surgery and include structural and nonstructural valve dysfunction, endocarditis, thrombo-embolism and bleeding events.

Secondary endpoints, particular to TAVI, should also include valve area and transvalvular gradient measurement, paravalvular leaks, device migration, emergency valve-invalve implantation, conversion to conventional surgery, and vascular complications.

These trials should be performed according to the standards for clinical trials, i.e. central data collection and analysis, data and safety monitoring board, core laboratory analysis, and auditing and quality control, all respecting the rules of independence from sponsors.

TAVI should currently be performed only in clinical studies or as part of post-marketing registries. Clinical trials should be limited to centres with experience in TAVI and trials, and which actively participate in internal evaluation.

In centres performing TAVI, multi-disciplinary meetings should be held on a regular basis to discuss indications, procedural techniques, and case outcomes. Hospitals should keep proof of close medico-surgical collaboration and maintain a log of all patients referred for TAVI, regardless of final treatment strategy, for continuous evaluation of the programme [35]. Furthermore, a series of thorough quality assurance measures should be included.

\section{Conclusion}

The currently available results obtained with TAVI suggest that these techniques are feasible and provide haemodynamic and clinical improvement for up to 2 years in patients with severe symptomatic AS at high risk or with contraindications for surgery. Pending questions concern mainly safety and long-term durability. Surgeons and cardiologists must work as a team to select the best candidates, perform the procedure, and, finally, evaluate the results. Today, these techniques are targeted at high-risk patients but they may be extended to the lower risk group in the future, if the initial promise holds true after careful evaluation. We are currently at the stage of evaluation, and a careful commercialization process including training and post-market surveillance is crucial to avoid the risk of uncontrolled diffusion, which is wholly undesirable at this stage of evolution of these techniques. 


\section{References}

[1] Nkomo VT, Gardin JM, Skelton TN, Gottdiener JS, Scott CG, EnriquezSarano M. Burden of valvular heart diseases: a population-based study. Lancet 2006;368:1005-11.

[2] lung B, Baron G, Butchart EG, Delahaye F, Gohlke-Bärwolf C, Levang OW, Tornos P, Vanoverschelde JL, Vermeer F, Boersma E, Ravaud P, Vahanian A. A prospective survey of patients with valvular heart disease in Europe: The Euro Heart Survey on valvular disease. Eur Heart J 2003;24:1231-43.

[3] American College of Cardiology/American Heart Association Task Force on Practice Guidelines, Society of Cardiovascular Anesthe-siologists, Society for Cardiovascular Angiography Interventions, Society of Thoracic Surgeons; Bonow RO, Carabello BA, Kanu C, de Leon AC Jr, Faxon DP, Freed MD, Gaasch WH, Lytle BW, Nishimura RA, O'Gara PT, O'Rourke RA, Otto CM, Shah PM, Shanewise JS, Smith SC Jr, Jacobs AK, Adams CD, Anderson JL, Antman EM, Faxon DP, Fuster V, Halperin JL, Hiratzka LF, Hunt SA, Lytle BW, Nishimura R, Page RL, Riegel B. ACC/AHA 2006 guidelines for the management of patients with valvular heart disease: a report of the American College of Cardiology/American Heart Association Task Force on Practice Guidelines (Writing Committee to revise the 1998 Guidelines for the Management of Patients with Valvular Heart Disease): developed in collaboration with the Society of Cardiovascular Anesthesiologists: endorsed by the Society for Cardiovascular Angiography and Interventions and the Society of Thoracic Surgeons. Circulation 2006;114:e84-e231.

[4] Vahanian A, Baumgartner H, Bax J, Butchart E, Dion R, Filippatos G, Flachskampf F, Hall R, lung B, Kasprzak J, Nataf P, Tornos P, Torracca L, Wenink A. Task Force on the Management of Valvular Heart Disease of the European Society of Cardiology; ESC Committee for Practice Guidelines. Guidelines on the management of valvular heart disease: The Task Force on the Management of Valvular Heart Disease of the European Society of Cardiology. Eur Heart J 2007;28:230-68.

[5] Kolh P, Kerzmann A, Honore C, Comte L, Limet R. Aortic valve surgery in octogenarians: predictive factors for operative and long term results. Eur J Cardiothorac Surg 2007;31:600-6.

[6] Melby SJ, Zierer A, Kaiser YP, Guthrie TJ, Keune JD, Schuessler RB, Pasque MK, Lawton JS, Moazami N, Moon MJ, Damiano Jr RJ. Aortic valve replacement in octogenarians. Risk factors for early and late mortality. Ann Thorac Surg 2007;83:1651-7.

[7] lung B, Cachier A, Baron G, Messika-Zeitoun D, Delahaye F, Tornos P, Gohlke-Bärwolf C, Boersma E, Ravaud P, Vahanian A. Decision-making in elderly patients with severe aortic stenosis: why are so many denied surgery? Eur Heart J 2005;26:2714-20.

[8] Cribier A, Eltchaninoff H, Bash A, Borenstein N, Tron C, Bauer F, Derumeaux G, Anselme F, Laborde F, Leon MB. Percutaneous transcatheter implantation of an aortic valve prosthesis for calcific aortic stenosis: first human case description. Circulation 2002;106:3006-8.

[9] Vassiliades TA Jr, Block PC, Cohn LH, Adams DH, Borer JS, Feldman T, Holmes DR, Laskey WK, Lytle BW, Mack MJ, Williams DO; Society of Thoracic Surgeons (STS), American Association for Thoracic Surgery (AATS), Society for Cardiovascular Angiography Interventions (SCAI), American College of Cardiology Foundation (ACCF), American Heart Association (AHA). The clinical development of percutaneous heart valve technology: a position statement of the Society of Thoracic Surgeons (STS), the American Association for Thoracic Surgery (AATS), and the Society for Cardiovascular Angiography and Interventions (SCAI). Ann Thorac Surg 2005;79:1812-8.

[10] Rosengart TK, Feldman T, Borger MA, Vassiliades TA Jr, Gillinov AM, Hoercher KJ, Vahanian A, Bonow RO, O'Neill W. Percutaneous and minimally invasive valve procedures. A scientific statement from the American Heart Association Council on Cardiovascular Surgery and Anesthesia, Council on Clinical Cardiology, Functional Genomics and Translational Biology Interdisciplinary Working Group, and Quality of Care and Outcomes Research Interdisciplinary Working Group. Circulation 2008;117:1750-67.

[11] De Jaegere P, Van Dijk LC, Laborde JC, Sianos G, Orellana Ramos FJ, Lighart J, Kappetein AP, van der Ent M, Serruys PW. True percutaneous implantation of the CoreValve aortic valve prosthesis by the combined use of ultrasound guided vascular access. Prostar ${ }^{\circledR} \mathrm{XL}$ and the TandemHeart ${ }^{\circledR}$. Eurolntervention 2007;2:500-5.

[12] Cribier A, Eltchaninoff H, Tron C, Bauer F, Agatiello C, Sebagh L, Bash A, Nusimovici D, Litzler PY, Bessou JP, Leon MB. Early experience with percutaneous transcatheter implantation of heart valve prosthesis for the treatment of end-stage inoperable patients with calcific aortic stenosis. J Am Coll Cardiol 2004;43:698-703.

[13] Cribier A, Eltchaninoff H, Tron C, Bauer F, Agatiello C, Nercolini D, Tapiero S, Litzler PY, Bessou JP, Babaliaros V. Treatment of calcific aortic stenosis with the percutaneous heart valve: mid-term follow-up from the initial feasibility studies: the French experience. J Am Coll Cardiol 2006;47:1214-23.

[14] Grube E, Laborde JC, Gerckens U, Felderhoff T, Sauren B, Buellesfeld L, Mueller R, Menichelli M, Schmidt T, Zickmann B, Iversen S, Stone GW. Percutaneous implantation of the CoreValve self-expanding valve prosthesis in high-risk patients with aortic valve disease: the Siegburg first-inman study. Circulation 2006;114:1616-24.

[15] Webb JG, Chandavimol M, Thompson CR, Ricci DR, Carere RG, Munt BI, Buller CE, Pasupati S, Lichtenstein S. Percutaneous aortic valve implantation retrograde from the femoral artery. Circulation 2006;113: 842-50.

[16] Webb JG, Pasupati S, Humphries K, Thompson C, Altwegg L, Moss R, Sinhal A, Carere RG, Munt B, Ricci D, Ye J, Cheung A, Lichtenstein SV. Percutaneous transarterial aortic valve replacement in selected high-risk patients with aortic stenosis. Circulation 2007;116:755-63.

[17] Grube E, Schuler G, Buellesfeld L, Gerckens U, Linke A, Wenaweser P, Sauren B, Mohr FW, Walther T, Zickmann B, Iversen S, Felderhoff T, Cartier $\mathrm{R}$, Bonan R. Percutaneous aortic valve replacement for severe aortic stenosis in high-risk patients using the second- and current third-generation self-expanding CoreValve prosthesis: device success and 30-day clinical outcome. J Am Coll Cardiol 2007;50:69-76.

[18] Lichtenstein SV, Cheung A, Ye J, Thompson CR, Carere RG, Pasupati S, Webb JG. Transapical transcatheter aortic valve implantation in humans: initial clinical experience. Circulation 2006;114:591-6.

[19] Walther T, Falk V, Borger MA, Dewey T, Wimmer-Greinecker G, Schuler G, Mack M, Mohr FW. Minimally invasive transventricular beating heart aortic valve implantation - proof of concept. Eur J Cardiothorac Surg 2007;31: 9-15.

[20] Walther T, Simon P, Dewey T, Wimmer-Greinecker G, Falk V, Kasimir MT, Doss M, Borger MA, Schuler G, Glogar D, Fehske W, Wolner E, Mohr FW, Mack M. Transapical minimally invasive aortic valve implantation: multicenter experience. Circulation 2007;116(Suppl.):I240-5.

[21] Ye J, Cheung A, Lichtenstein SV, Pasupati S, Carere RG, Thompson CR, Sinhal A, Webb JG. Six-month outcome of transapical transcatheter aortic valve implantation in the initial seven patients. Eur J Cardiothorac Surg 2007;31:16-21.

[22] Edwards FH, Peterson ED, Coombs LP, DeLong ER, Jamieson WR, Shroyer ALW, Grover FL. Prediction of operative mortality after valve replacement surgery. J Am Coll Cardiol 2001;37:885-92.

[23] Roques F, Nashef SA, Michel P, EuroSCORE study group. Risk factors for early mortality after valve surgery in Europe in the 1990s: lessons from the EuroSCORE pilot program. J Heart Valve Dis 2001;10: $572-7$.

[24] STS National Database. STS US Cardiac Surgery Database: 1997 Aortic Valve Replacement Patients: Preoperative Risk Variables. Chicago: Society of Thoracic Surgeons; 2000. http://www.ctsnet.org/doc/3031. (10 May 2006).

[25] Ambler G, Omar RZ, Royston P, Kinsman R, Keogh BE, Taylor KM. Generic, simple risk stratification model for heart valve surgery. Circulation 2005;112:224-31.

[26] Dewey TM, Brown D, Ryan WH, Herbert MA, Prince SL, Mack MJ. Reliability of risk algorithms in predicting early and late operative outcomes in highrisk patients undergoing aortic valve replacement. J Thorac Cardiovasc Surg 2008;135:180-7.

[27] Schelbert EB, Vaughan-Sarrazin MS, Welke KF, Rosenthal GE. Hospital volume and selection of valve type in older patients undergoing aortic valve replacement surgery in the United States. Circulation 2005;111: 2178-82.

[28] Lee SJ, Lindquist K, Segal MR, Covinsky KE. Development and validation of a prognostic index for 4-year mortality in older adults. JAMA 2006;295:801-8 [Erratum in JAMA 2006;295:1900].

[29] Tops LF, Wood DA, Delgado V, Schuijf JD, Mayo JR, Pasupati S, Lamers FPL, van der Wall EE, Schalij MJ, Webb JG, Bax JJ. Noninvasive evaluation of the aortic root with multislice computed tomography: implications for transcatheter aortic valve replacement. J Am Coll Cardiol Imaging, in press.

[30] Moss RR, Ivens E, Pasupati S, Humphries K, Thompson CR, Munt B, Sinhal A, Webb JG. Role of echocardiography in percutaneous aortic valve implantation. J Am Coll Cardiol Imaging 2008;1:15-24. 
[31] Zegdi R, Ciobotaru V, Noghin M, Sleilaty G, Lafont A, Latremouille C, Deloche A, Fabiani JN. Is it reasonable to treat all calcified stenotic aortic valves with a valved stent? Results form a human anatomic study in adults. J Am Coll Cardiol 2008;51:579-84.

[32] Ludgate S. A user's guide to overcoming roadblocks: the European approval process. Eurolntervention 2006;1(Suppl. A):A79-80.

[33] Zuckerman BD. The FDA role in the development of percutaneous heart valve technology. Eurolntervention 2006;1(Suppl. A):A75-8.
[34] Grunkemeier GL, Jin R, Starr A. Prosthetic heart valves: objective performance criteria versus randomised clinical trial. Ann Thorac Surg 2006;82:776-80.

[35] Descoutures F, Himbert D, Lepage L, lung B, Detaint D, Tchetche D, Brochet E, Castier Y, Depoix JP, Nataf P, Vahanian A. Contemporary surgical or percutaneous management of severe aortic stenosis in the elderly. Eur Heart J 2008; epub ahead of print 6 March. 